\title{
Field study of complements to supervisory leadership in more and less flexible work settings
}

\author{
Terri L. Griffith ${ }^{1^{*}}$ DD, Emma S. Nordbäck², John E. Sawyer ${ }^{3}$ and Ronald E. Rice ${ }^{4}$
}

\footnotetext{
* Correspondence: t@terrigriffith.com ${ }^{1}$ Leavey School of Business, Santa Clara University, 500 El Camino Real, Santa Clara, CA 95053, USA Full list of author information is available at the end of the article
}

\begin{abstract}
Self-management is increasingly required by people in jobs with flexible schedules and locations, freelance arrangements, and other forms of organizational job design. Successful self-management requires a sense of engagement with one's work. We build from the substitutes for leadership literature to develop a model of work design focused on how complements to supervisory leadership foster work engagement. The model illustrates a parsimonious set of possible complements to supervisory leadership: feedback from the work itself, technology support of work, knowledge to work independently, electronic communication with supervisors, and alternative workplace use as predictors of work engagement. Results are from a two-period field study of a Nordic telecom company experienced with flexible work practices. Additionally, in time 2, we compare the data from this first organization with a Nordic transportation company that is less experienced with flexible work practices. Our results show the strongest relationships with work engagement are feedback from the work itself and technology support of work. Supervisor electronic communication also plays a role in work engagement, mediated by alternative workplace use. We highlight shifts in work design that can enable more flexible work settings while maintaining worker engagement in our increasingly digital organizations.
\end{abstract}

Keywords: Complements to supervisory leadership, Substitutes for leadership, Flexible work, Engagement, Work design, Digital organizations, Telecommuting, Feedback
The future of organizations is bright with opportunities to leverage technology and new perspectives on work and organizational boundaries. Snow et al. (2017), for example, provide a framework for the design of what they call digital organizations (e.g., organizations relying on digital technology across operations and communication). They highlight the importance of self-organization and taking opportunities to combine people, technology, and organizational design in new ways for effective and efficient work. Examples of such changes include virtual work, such as telecommuting (Gajendran and Harrison 2007), virtual teams (Gilson et al. 2015), independent contractors with simultaneous jobs of varying duration (e.g., gig work, Stanford 2017), work augmented using artificial intelligence (Brynjolfsson and Mitchell 2017), and more. Our field must rethink organizational designs given these changes in how work is done (Barley et al. 2017; Forman et al. 2014; Galbraith 2012; Snow et al. 2017).

(C) The Author(s). 2018 Open Access This article is distributed under the terms of the Creative Commons Attribution 4.0 International License (http://creativecommons.org/licenses/by/4.0/), which permits unrestricted use, distribution, and reproduction in any medium, provided you give appropriate credit to the original author(s) and the source, provide a link to the Creative Commons license, and indicate if changes were made. 
In such changing contexts, self-management (e.g., Fjeldstad et al. 2012; Petrou et al. 2012), knowledge commons, protocols, and infrastructure (Fjeldstad et al. 2012) may be more effective than traditional hierarchical control (Snow et al. 2017), such as formal supervision. Here, we acknowledge this trend and look to the literature on work design for foundational dimensions that may serve to complement traditional supervisory leadership. Morgeson and Humphrey (2008), for example, offer task, social, and contextual sources of work characteristics as an integrative approach to describing work. We specifically highlight the aspects of work design that serve as complements to supervisory leadership in the development of worker engagement. This complements approach leverages Kerr and Jermier's (1978) substitutes for leadership concepts (i.e., characteristics of the person, work, or organization that can substitute, neutralize, or enhance leadership behaviors), as well as more recent work acknowledging the full range of leadership sources and their effects (e.g., Avolio et al. 2014; Hoch and Kozlowski 2014). That is, rather than fully substituting for leadership, the new digital contexts involving more self-management provide possibilities for complements to formal supervision that may enhance work engagement.

While substitutes for leadership research finds mixed support (see Dionne et al. 2005 for a nuanced exchange of theoretical letters on the topic), we see an opportunity to reconsider its importance in more digital organizations. We take the opportunity to bring to the foreground aspects of the substitutes for leadership construct that might more precisely be called joint effects (Dionne et al.) as they work alongside supervisory leadership. That is, we do not argue for the replacement of supervision, but rather consider how aspects of work design (across task, social, contextual sources) can complement supervisory leadership. The topic itself is more important in settings with greater distribution of work across time, locations, people, technology, and employment categories, where there is less opportunity (and perhaps need) for the application of traditional supervisory leadership (Avolio et al. 2014; Bonet and Salvador 2017; Hoch and Kozlowski 2014).

Our focus is on worker engagement. Worker engagement offers the ability to predict performance (Zhong et al. 2016) and as a topic of keen interest (and concern) from managers (Gallup 2017) and scholars (Gerards et al. 2018; Knight et al. 2017) alike. Engagement is also especially important in settings where outcomes are hard to observe (Leiter and Bakker 2010). Moreover, due to the diminished opportunities of leaders to influence and motivate their subordinates over distance, location, and time in the new digital contexts (Bonet and Salvador 2017; Hoch and Kozlowski 2014), it is more likely that workers' engagement in their work is vital. Thus, our work is aligned with the recent call by Oldham and Fried (2016) to examine the impact of new work environments on employees' job characteristics and engagement.

We first theoretically develop our model of central complements to supervisory leadership that should foster work engagement and then assess it within two large Nordic organizations with differing flexible work norms, using one to test the model over time and the other to validate and compare the results across settings. The results show the value of feedback from the task itself, as well as technology support of work, use of alternative workplaces, and electronic communication with supervisors-all typical possibilities for complements to supervisory leadership in today's work environment. We contribute to a growing body of research on leadership (substitutes and complements) in the context of technologically supported settings, as well as speak to aspects of 
research on work design in digital organizations characterized by more and less distributed and flexible work environments (Gibson et al. 2011; Snow et al. 2017).

\section{Substitutes for and complements to leadership}

Kerr and Jermier (1978) broadened the perspective on the dynamics of organizational leadership by examining substitutes, neutralizers, and enhancers of leadership behaviors. They proposed that characteristics of the subordinate (e.g., ability), the task (e.g., feedback), and organization (e.g., cohesive work groups) can substitute for some basic leadership behaviors (e.g., initiating structure and consideration). Shared cognition in teams can substitute for parallel leadership actions (e.g., temporal coordination, Santos et al. 2016). Organizational routines serve a similar purpose, removing the need to debate and negotiate many common and frequent activities, thus creating situations that allow workers to move forward without specific leadership directives (Nelson and Winter 1982; Rice and Cooper 2010).

Full reviews of this literature are provided by Jermier and Kerr (1997) and Dionne et al. (2005). However, a key nuance noted by Dionne et al. is that not all substitutes are substitutes. Rather, Kerr and Jermier (1978) allude to a variety of relationships, including the possibility of joint effects where "substitutes" work in contexts that also include supervisory leadership. Our research takes this focus and uses the term complements to keep the distinction clear (responding to an admonition in Dionne et al. for greater specificity).

Beyond Kerr and Jermier (1978), other scholars also considered changes in the need for and forms of organizational hierarchies (Cleveland 1985; Huber 1990; Lawler 1988). Triggers included costs, inefficiencies, and transmission errors in hierarchical structures, and the increased interest in self-managed work (Lawler 1988). Other analyses pointed to the rise of organizational information and communication technologies (ICTs), which began to obviate the need for mid-level managers as information gatekeepers and filters (Huber 1990; Taylor and Van Every 1993), and allowed organizational members to overcome time and location constraints on work coordination and accomplishment (Rice 1980; Rice and Bair 1984). Huber explicitly considered how organizational ICTs would reduce the number of organizational levels involved in authorization, and lessen high organizational centralization, due to easier, faster, and broader access to information. More sociologically, Cleveland (1985) was one of the first to argue that the growing information environment provided resources that could bypass traditional hierarchies, especially those based on control of knowledge and expertise, requiring us "to rethink the nature of leadership" (p. 185).

We offer results related to how complements to supervisory leadership can have effects in the context of digital organizations with their often flexible work practices. In the following review, we will use the term found in the mentioned research-most often substitutes as noted above-but our contribution draws on how this work relates to situations where supervisory leadership also operates, such as where supervisory leadership is complemented by characteristics of the subordinate, task, organization, and/or tools.

Empirical research on leadership in digital organizations is sparse. Hoch and Kozlowski (2014) call the research base on virtual team leadership "limited" (p. 390), and Avolio et al. (2014) note that "we have relatively little understanding of the 
potential effects of these [advanced information] technologies on the leadership dynamic in or outside organizations" (p. 126). While we do have some research on traditional supervisory leadership (Hoch and Kozlowski 2014), shared leadership in virtual teams (Hoch and Kozlowski 2014), self-leadership in self-managing teams (Millikin et al. 2010), structural supports in virtual teams (performance management systems, Hoch and Kozlowski 2014), and contingencies related to the impact of manager-worker separation (Bonet and Salvador 2017), we lack knowledge about how complements to supervisory leadership operate from an individual's perspective, such as in influencing the individual's work engagement.

Breevaart et al. (2016) offer an example of individual leadership dynamics for a largely business service and healthcare sample. Using a diary methodology, they found that both self-leadership (e.g., employees assuming responsibilities) and transformational leadership predicted work engagement, depending on the worker's need for leadership that week. Thus, we have evidence for one complement to supervisory leadership (selfleadership) in organizations that are likely to be at least somewhat digital.

We believe that the importance of complements to supervisory leadership should be especially pronounced in work environments where individuals work independently, or self-manage, such as in flexible work settings, given the concomitant reduction in opportunity for shared (e.g., D’Innocenzo et al. 2016; Hoch and Kozlowski 2014) or face-to-face leadership (Bonet and Salvador 2017). Thus, we take this opportunity to examine complements to supervisory leadership on one outcome important to self-managed and flexible jobs: work engagement (as justified below).

\section{Complements for supervisory leadership model development}

Figure 1 presents our proposed model and associated hypotheses to guide the following discussion. The model uses selected concepts from each of Morgeson and Humphrey's (2008) task, social, and contextual categories and focuses on characteristics especially aligned with the context of digital organizations at the individual level of analysis. The work characteristics of feedback from the work itself (task), technology support (context), knowledge to work independently (task), supervisor electronic communication (social), and alternative workplace use (context) provide a foundation for our initial consideration of complements to supervisory leadership and engagement.

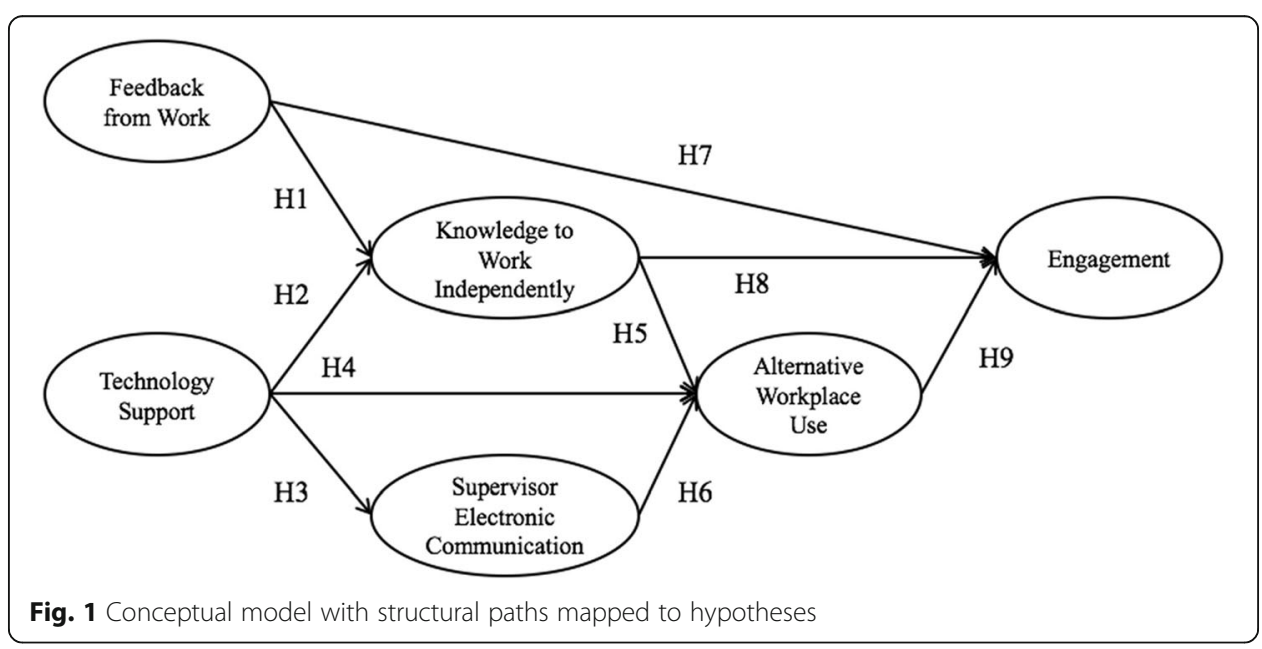


In addition, we note Kerr and Jermier's (1978) argument that some workers do not need substantial structuring or emotional support from leaders, as they may obtain these via their self-leadership (e.g., Stewart et al. 2011), find it in routines, and/or acquire it from other workers (see also Breevaart et al. 2016, discussion of need for leadership). We see this initial integration within a single model as a step forward given the inclusion of key categories of work design and the effort (described below) to place these characteristics in relation to one another-an area noted as valuable for future research (Morgeson and Humphrey 2008; Parker et al. 2017). We also acknowledge that this model includes only a subset of all the possible antecedents to work engagement, bounded here by the focus on work design in digital organizations.

Work engagement is our focal dependent variable. Engagement is critical in work settings that include distributed and flexible work practices with often hard-to-observe outcomes such as creativity and initiative (Leiter and Bakker 2010) and performance (e.g., Bakker et al. 2012; Breevaart et al. 2016; Rich et al. 2010; Salanova et al. 2005; Zhong et al. 2016). Engagement is also an important topic in the management practice literature (Willis Towers Watson 2017), following from Gallup survey data noting that the majority of employees (worldwide) are not engaged with their jobs (2017).

Our model highlights the direct and mediating effects of complements for supervisory leadership on work engagement, rather than considering complements as moderators, following Kerr and Jermier's (1978) work and Podsakoff et al. (1993) meta-analysis' conclusions. We justify the relationships in hypothesis order, shown in Fig. 1 above.

\section{Factors supporting knowledge to work independently}

Knowledge to work independently is necessary for flexible, individual work. People come to their jobs with some level of knowledge and are often chosen for flexible work opportunities based on task skills (D'Souza and Colarelli 2010). Feedback from the work, and technology support of work, are included here as antecedents as they serve as complements to supervisory leadership that allow individuals to obtain and build the knowledge they need to do their work at least somewhat independently of their supervisor.

\section{Feedback from the work itself}

Ilgen et al.'s (1979) discussion of feedback, building on the work of Annett (1969) and Bilodeau (1966), identifies three main sources of feedback: observers (other workers/supervisors), the work itself, and self-feedback. Feedback from the work environment is a basic component of human factor engineering (McCormick 1970), job enrichment (Hackman and Oldham 1975), and how knowledge is developed (Ilgen et al. 1979; Pierce et al. 2009). Task-provided feedback is the most immediate (Hall and Lawler 1968) and accurate source of feedback (Campbell et al. 1970). Task feedback is more informative than feedback originating from the supervisor (Greller and Herold 1975), which makes it critical to developing the knowledge to work independently, especially when people work at alternative sites away from their supervisor. Other research has also found that task feedback improves learning (Goodman 1998), thus generating competence and knowledge to work independently. 
Hypothesis 1: Feedback from the work itself is positively related to knowledge to work independently.

\section{Technology support of work}

Appropriate use of information and communication technology can complement and support work and is foundational to the design of the digital organization (Brynjolfsson and McAfee 2014). For example, Mark (2002) found that technology and human activities combined provided greater access to information than face-to-face interaction alone. Greater access to information, in turn, provides individuals with increased autonomy and thus ability to work independently (Bloom et al. 2014). Dascal and Dror (2005) point to the impact of technology on human cognition: "Cognition used to be thought of as largely individual-based, but with the advent of the web and other new technologies it is becoming clear that cognition can also be distributed across different agents, both human and virtual" (p. 454). Other studies point to the value of the increased transparency that technology brings to work (Tapscott and Ticoll 2003). Work management systems (Vanderfeesten and Reijers 2006), for example, improve insights into work process execution, e.g., knowing what to do next in your task. These studies provide evidence that technology may provide information and support to aid in decision-making and an individual's ability to work independently. Feedback from supervisors is reduced (Bonet and Salvador 2017; Gibson et al. 2011) where there is temporal and spatial dispersion of work. In these work arrangements, augmented feedback is necessary and extensively available through the general technological support of work (Rice and Leonardi 2013), which aids in the development of knowledge to work independently.

Hypothesis 2: Technology support of work is positively related to knowledge to work independently. ${ }^{1}$

\section{Factors supporting supervisor electronic communication}

As noted above, our goal is to broaden the question of how aspects of work design can contribute to, and/or complement, supervisory leadership, rather than to focus solely on substituting for, or neutralizing, supervisory leadership. Indeed, as Lawler (1988) argued, not all supervisory functions can or should be substituted, depending on context, and not all workers or all managers wish to substitute several of those functions. Consideration of supervisor electronic communication allows us to consider a social aspect of work design, as well as the more commonly considered task and contextual aspects (e.g., Morgeson and Humphrey 2008).

\section{Technology support of work}

The more technically supported the work environment, the more able and likely people are to use technology to connect with their coworkers and supervisors (Rice and Leonardi 2013). Additionally, where there is increased transparency from technology support in the workflow, workers (including supervisors) gain more knowledge about who knows what and their position and role in the social network (Leonardi 2014). This may both enable and trigger increased communication, including communication with supervisors. It may also be the case that increased technological support for work introduces 
more abstractions and potential complications, which in turn would generate a greater need for communicating about explanations and solutions with one's supervisor, who, due to the employee's flexible work situation, is not temporally or spatially proximate.

Hypothesis 3: Technology support of work is positively related to supervisor electronic communication.

\section{Factors supporting alternative workplace use}

As noted earlier, many organizations have adopted flexible work arrangements to provide workers more control over where and when they perform work (Kossek and Michel 2011). While our model assumes that there is a formal office to choose to work away from, we expect that the ability to have alternative options for one's work location and time would also be valuable in settings without a formal office as well, especially, for example, for freelance workers. Technology support of work, knowledge to work independently, and supervisor electronic communication are key influences on the use of alternative workplaces. Each brings a component of support that allows and motivates work to be done away from a traditional office.

\section{Technology support of work}

The development of advanced communication and information technologies allows many types of work to be conducted anytime or place (e.g., Rice 2017). Use of technology to work away from the office falls under several different names: telecommuting (Nilles 1982), flexible work (Olson 1983), and virtual work (Wiesenfeld et al. 1999), as examples. To engage with these kinds of work, one must not only have access to technologies that support communicating with supervisors, coworkers, clients, and others, but also to those who support and guide one in accomplishing the work. Technology support of work may reduce functional impediments to working away from the office, offering the opportunity to take advantage of alternative workplace use.

Hypothesis 4: Technology support of work is positively related to alternative workplace use.

\section{Knowledge to work independently}

Our model proposes knowledge to work independently as supportive of alternative workplace use. Requisite knowledge and ability are foundational to the ability to work away from the traditional office. Additionally, the opportunity to choose an alternative workplace is more likely to be allowed for professional, well-educated workers (Haddon and Brynin 2005; Ruth 2011) who tend to be highly skilled and self-managed in their work. These knowledge workers, being experts on their tasks, commonly expect to receive more autonomy from their leader (Davenport 2005). We extend this to where and when they perform their work.

Hypothesis 5: Knowledge to work independently is positively related to alternative workplace use.

\section{Supervisor electronic communication}

Since use of alternative workplaces by definition means that the worker is not collocated with the supervisor, the supervisor's ability and willingness to communicate electronically is an influence on a worker's opportunity to work away from the office. Motivation to 
work at an alternative workplace is also affected as, regardless of work feedback, technology support of work, and/or knowledge to work independently, these are not likely to completely replace supervisor interpersonal interaction, especially when it comes to decisions about where and when to work. Supervisor support of, or resistance to, flexible work is often a major influence in employee access to, and decision to use, flexible work arrangements (Bakker et al. 2008; Kossek and Michel 2011; Leslie et al. 2012; Rice 2017).

Additionally, supervisor electronic communication complements face-to-face communication with the supervisor and thus enables workers to use alternative workplaces. Raghuram et al. (2001) found that organizational connectedness and interpersonal trust enabled greater adjustment to virtual work, including workers' motivation to work outside of the office. Additionally, "Knowledge workers in distributed work environments require substantial communication with colleagues and supervisors to perform their work activities, and collaborative technologies, like groupware, continue to improve the potential for such communication" (Bélanger and Allport 2008, p. 101). Electronic communication with one's supervisor can loosen time, space, social interaction, and knowledge constraints and provide more resources and communication for accomplishing work and improving the results from invested time and effort (Kubicek et al. 2014).

Hypothesis 6: Supervisor electronic communication is positively related to alternative workplace use.

\section{Work engagement}

Engagement has a rich and complicated background (Saks 2006). We begin with the conceptualization offered by Schaufeli and colleagues (Petrou et al. 2012; Schaufeli and Bakker 2004; Schaufeli et al. 2006), given their application of the engagement construct to work design and job crafting. Work engagement is a positive, fulfilling, work-related state of mind involving vigor (e.g., high levels of energy and mental resilience), dedication (e.g., sense of significance and enthusiasm), and absorption (e.g., concentration and flow) (Schaufeli and Bakker 2004). Engaged workers, in turn, are more likely to be more creative, productive, and willing to go the extra mile (Bakker et al. 2008).

In their examination of the antecedents to engagement, Schaufeli and Bakker (2004) focused on job resources and demands at the task, interpersonal, and organizational level (performance feedback, support from colleagues, and supervisory coaching). Here, we leverage complements to supervisory leadership, focusing on feedback from the work itself (task characteristic of the work), knowledge to work independently (task characteristic of the worker), and alternative workplace use (contextual characteristic of the work). We also consider the mediated effects of technology support of work (contextual characteristic of the work), and supervisor electronic communication (social characteristic of the work). Below, and consistent with Schaufeli and Bakker (2004), we see engagement as supported by the achievement of work goals and the reduction of energy-depleting constraints. We outline the specific relationships, their support, and predicted outcomes, below.

\section{Feedback from the work itself}

Work design characteristics fitting our definition of complements to supervisory leadership are generally found to relate to work engagement (e.g., Saks 2006). Schaufeli and 
Bakker (2004), for example, found a positive relationship between performance feedback and work engagement. Xanthopoulou et al. (2009) reported related results, and added the positive effects of autonomy at work and opportunity for professional development on work engagement. In a digitalized work environment characterized by independent workers, and work increasingly done away from the traditional office, feedback from the work itself is a prominent work characteristic affecting work engagement.

Hypothesis 7: Feedback from the work itself is positively related to work engagement.

\section{Knowledge to work independently}

The influence of complements to supervisory leadership on work engagement can also be mediated by knowledge to work independently (i.e., as knowledge becomes tacit through experience, Nonaka 1994). Previous research has suggested that structural design choices such as job autonomy (e.g., Xanthopoulou et al. 2009) and self-leadership (Breevaart et al. 2016; Lovelace et al. 2007) increase work engagement through mechanisms such as a feeling of self-control, self-determination, purpose, and a sense of ownership (e.g., Stewart et al. 2011; Xanthopoulou et al. 2009). We expect that knowledge to work independently provides a similar mechanism.

Hypothesis 8: Knowledge to work independently is positively related to work engagement.

\section{Alternative workplace use}

Today's digitalized work environments are increasingly dispersed over space and time and defined by organizations and workers who try to match individual work preferences, organizational policies, and task requirements. Research on contexts where working away from a traditional office is part of employee-driven work design has found a positive link between flexible work options and outcomes such as increased employee work engagement, commitment, and attachment (Pitt-Catsouphes and Matz-Costa 2008). Both formal (an ongoing work arrangement) and occasional (ad hoc use of flexibility by varying work hours and occasional work away from the office) use of flexibility have been positively associated with employee work engagement and retention (Richman et al. 2008). This positive relationship to engagement can be explained by an employee's increased resources and own control to meet the demands of both personal and work domains. A meta-analysis conducted by Gajendran and Harrison (2007) furthermore showed that telecommuting is positively related to job satisfaction, job performance, and reduced stress, all related to work engagement. Thus, we expect that alternative workplace use will increase engagement with the work itself (e.g., Rice 2017), especially in a work context where flexible work is a more supported option.

Hypothesis 9: Alternative workplace use is positively related to work engagement.

(Please see Fig. 1 for a summary of the proposed hypotheses.)

\section{Method}

\section{Sample and procedure}

\section{The organizations}

We recruited two organizations, Org1, a large Nordic telecommunications company, and Org2, a large Nordic transportation company, into a 2-year research project focused on broad issues of work life. While we intended to engage both organizations 
across two periods of assessment, Org2, unfortunately, was not able to participate in the first wave of data collection. This research design did, however, enable us to test the model over time within Org1 (T1-T2) and then validate the results across settings (Org1 and Org2, T2). Org2 provides a useful comparison in that the two organizations differ in the culture for flexible work practices. Lawler (1988) also noted that values and beliefs play a major role in the success of substituting for hierarchy-by both the workers and management. That is, either may favor or dislike a lessening of formal leadership. Not all employees wish to be much engaged in their work, and not all managers or organizations support flexible work. By analyzing the model and comparing model parameters across two dissimilar organizations, we test the robustness of the overall model.

The data for the first analysis (a panel causal model in Org1) were collected by a web-based survey (T1) and then a year later (T2) using the same system. Data for the second analysis (comparing the cross-sectional causal model across two organizations) were collected only in T2 (Org1 and Org2). We chose the participating organizations because Org1 was generally supportive of all types of flexible work, while Org2 was less open to flexibility and required most work to occur at the office, thus providing variance in the main influence under study, flexible work use. Before the survey, we had several rounds of discussions with Human Resources personnel and executives in both organizations, which gave us a better understanding of the organizational contexts and suggested appropriate wording for some of the survey questions.

Org1 employs over 25,000 employees worldwide and has about 1500 workers in the Finnish headquarters where we collected the data. This site works in close collaboration with other Finnish sites as well as with other Nordic locations. Hence, the majority of the workers in the company had some experience working with people from different sites. Org1 has a long history of using flexible work practices, allows flexible work throughout, and has a culture supportive of flexible work. Their formal guidelines define flexible work as "work in which the working time and place can be selected individually." Additionally, one of their aims for flexible work is "to enhance the employees' ability to manage their work, and to facilitate self-directed pacing of work."

Org2 employs about 7000 workers worldwide, with most knowledge workers based in Finland at the data collection site, the company headquarters, with 900 workers. Work is predominantly performed at the office and flexible work is less supported-only on a special occasion basis. People rarely reported working away from the office, often because they did not know it was an option and/or because they were not allowed or discouraged from it. We often heard that the organizational culture "doesn't know about telework" or "flexwork has never been an accepted way of working in this company."

Both organizations offered similar information and communication technologies (e.g., email, mobile phones, shared calendars, intranet, video and call conferencing, and instant messaging) to their workers, enabling virtual work from a technology infrastructure perspective. However, the workers' experience with technology-mediated work varied substantially across the two organizations. Pilot interviews suggested that in Org1 workers collaborated as easily through technology as through face-to-face, while in Org2 collaboration was perceived as tied to a physical space to be efficient for those involved. Org1 policies stated virtual participation in meetings to be a general right of workers, whereas in Org2 workers were expected to be at the office for meetings. Thus, 
the nature of flexible work and the technological experience, both grounded in different conceptualizations of the importance of traditional office hours and location, differ between the two organizations.

\section{Response rates and demographics}

We sent the survey to all members of each organization's national headquarters. In T1, for Org1 only, 838 usable responses were received (54.5\% response rate). $39.5 \%$ were female, nearly all worked full-time (98.3\%), the modal age was between 41 and 50 (38.4\%) years old, and the mean organizational tenure was 16.6 years $(\mathrm{sd}=9.6)$. In T2, we received 735 usable responses from Org1 (50.1\%) and 295 from Org2 (43.0\%). For Org1 and for Org2, respectively, females were $41.2 \%$ and $69.8 \%$, the modal age was $41-50$ years $(41.5 \%, 41.2 \%)$, and mean tenure was 17.5 years $(\mathrm{sd}=9.7)$ and 17.2 years $(\mathrm{sd}=11.0)$. Across T1 and T2 for Org1, the panel sample was 367 (43.8\% of the T1 respondents and 49.9\% of the T2 respondents), with $44.9 \%$ female, a modal age of $41-50$ (30.8\%), and mean tenure of 17.2 years $(\mathrm{sd}=9.4)$.

\section{Measures (see Appendix for item wording and response ranges)}

Knowledge to work independently, feedback from work, and technology support of work

While Kerr and Jermier offered the initial set of scales related to the underlying components of substitutes for leadership (foundational for our construct, complements to supervisory leadership), Podsakoff et al. (1993) provided an enhancement and Podsakoff and MacKenzie (1994) then presented a further refinement. As per past research (e.g., Dionne et al. 2002; Keller 2006), we used only the scales most related to our specific field context to keep the survey manageable for the organization and, in some cases, simplified them further given our need to translate into Finnish. Podsakoff and MacKenzie's (1994) three-item knowledge-focused sub-scale provided the basis for our scale of knowledge to work independently. We also used their three-item feedback-focused sub-scale to create our feedback from work scale. Finally, we added a three-item technology support of work scale based on the style of the Podsakoff and MacKenzie measures.

\section{Supervisor electronic communication}

We used the mean of three items that assessed frequency of communication with the respondent's supervisor via text messaging, phone, and email communication.

\section{Alternative workplace use}

We developed a large set of flexwork items following the organizational discussions. For this research, we used the items focused on sustained work times (at home, another company's location, hotel, library), excluding more transient or idiosyncratic places (e.g., taxi, cafeteria, or summer cottage). Alternative workplace usage was the mean frequency of use of the four alternative work locations.

\section{Work engagement}

Schaufeli et al. (2006) describe work engagement as a persistent and pervasive affective-cognitive state including work focused vigor, dedication, and absorption. We chose their three-item dedication sub-scale as having the greatest focus on the work 
itself. "Dedication refers to being strongly involved in one's work and experiencing a sense of significance, enthusiasm, inspiration, pride, and challenge" (p. 702).

\section{Results}

\section{Descriptive statistics and scales}

All scales had reliabilities greater than 0.8 , and all items loaded $(p<.01)$ on their assigned latent factors. Table 1 reports means, standard deviations, correlations, and, where appropriate, Cronbach's alpha for reliability of reflective scales for T1 and T2 for Org1 and T2 only for Org2. The patterns of means and correlations are similar across the two organizations with two notable exceptions. Alternative workplace use was lower for respondents in Org2 $(t=8.01, p<.01)$, and knowledge to work independently was positively correlated with alternative worksite use in Org2 $(r=.14, p<.05)$, but not in Org1 $(r=.06, p>.10)$. This is consistent with our observation that alternative worksite use is common and part of the culture at Org1, but is the exception in Org2.

\section{Model fit}

\section{Panel analysis of Org1}

We fit the expected measurement model to the observed measures for the reflexive latent variables: T1 feedback from work, T1 knowledge to work independently, T1 and T2 technology support of work, and T2 work engagement. The model fit $\left(\chi^{2}[80, n=367]=180.730, \chi^{2} / d f=2.259, \mathrm{CFI}=.972\right.$, RMSEA $\left.=.059\right)$ was within the

Table 1 Scale reliability (coefficient alpha), scale descriptive statistics, and correlations among study variables

\begin{tabular}{|c|c|c|c|c|c|c|c|c|}
\hline & $\begin{array}{l}\text { Alpha } \\
\mathrm{T} 1 / \mathrm{T} 2\end{array}$ & M & $\mathrm{SD}$ & Feedback & $\begin{array}{l}\text { Work } \\
\text { knowledge }\end{array}$ & $\begin{array}{l}\text { Tech } \\
\text { support }\end{array}$ & Engagement & $\begin{array}{l}\text { Supervisor } \\
\text { E-Com }\end{array}$ \\
\hline \multicolumn{9}{|l|}{ Organization $1 \mathrm{~N}=718$} \\
\hline $\begin{array}{l}\text { Feedback from work } \\
\text { itself }\end{array}$ & $.92 / .91$ & 5.28 & 1.07 & & & & & \\
\hline $\begin{array}{l}\text { Knowledge to work } \\
\text { independently }\end{array}$ & $.80 / .79$ & 5.80 & .84 & $.27^{* *}$ & & & & \\
\hline $\begin{array}{l}\text { Technology support } \\
\text { of work }\end{array}$ & $.86 / .85$ & 5.31 & 1.08 & $.37^{* *}$ & $.39^{* *}$ & & & \\
\hline Work engagement & $.94 / .94$ & 5.30 & 1.12 & $.49^{* *}$ & $.26^{* *}$ & $.41^{* *}$ & & \\
\hline $\begin{array}{l}\text { Supervisor elect. } \\
\text { communication }\end{array}$ & $\mathrm{n} / \mathrm{a}^{1}$ & 4.30 & 1.16 & $.20^{* *}$ & .06 & $.15^{* *}$ & $.27^{* *}$ & \\
\hline Alternative workplace & $\mathrm{n} / \mathrm{a}^{1}$ & 2.41 & .72 & $.10^{* *}$ & .06 & $.11^{* *}$ & $.17^{* *}$ & $.37^{* *}$ \\
\hline \multicolumn{9}{|l|}{ Organization 2 N=290 } \\
\hline $\begin{array}{l}\text { Feedback from work } \\
\text { itself }\end{array}$ & na/.92 & 5.01 & 1.14 & & & & & \\
\hline $\begin{array}{l}\text { Knowledge to work } \\
\text { independently }\end{array}$ & $\mathrm{na} / .86$ & 5.70 & 1.04 & $.31^{* *}$ & & & & \\
\hline $\begin{array}{l}\text { Technology support } \\
\text { of work }\end{array}$ & $\mathrm{na} / .79$ & 5.36 & .91 & $.37^{* *}$ & $.39 * *$ & & & \\
\hline Work engagement & na/.92 & 5.37 & 1.13 & $.43^{* *}$ & $.23^{* *}$ & $.28^{* *}$ & & \\
\hline $\begin{array}{l}\text { Supervisor elect. } \\
\text { communication }\end{array}$ & $\mathrm{n} / \mathrm{a}^{1}$ & 4.25 & 1.21 & $.17^{* *}$ & -.06 & .06 & $.22^{* *}$ & \\
\hline Alternative workplace & $\mathrm{n} / \mathrm{a}^{1}$ & 1.96 & .84 & $.23^{* *}$ & $.14^{*}$ & $.16^{* *}$ & $.22^{* *}$ & $.36^{* *}$ \\
\hline
\end{tabular}


normally accepted range (RMSEA $\leq .06$, SRMSR $\leq .08$, CFI $\geq .95$, and TLI $\geq .95$, Hu and Bentler 1999; Nye and Drasgow 2011). The top section of Table 2 shows the measurement parameters for each estimated factor loading and the critical ratio (CR) obtained by dividing the covariance estimate by its standard error. A CR of 1.96 or greater is significant at the $p=.05$ confidence level.

To estimate the predicted two-panel model, we then added T2 supervisor electronic communication and alternative workplace use as single indicator latent constructs, with the indicator being the mean of the possible forms of supervisor electronic communication and workplace use, respectively. Supervisor electronic communication and alternative workplace use are represented as single indicators because they are formative rather than reflective measures. Specifically, both variables are counts of the frequency with which the individual uses various forms of communication or workplaces. Because not all forms are equally likely and depend on one's situation, one may use one or a few forms exclusively.

Table 2 Unconstrained model measurement and structural parameter estimates for Org 1 panel analysis

\begin{tabular}{|c|c|c|c|c|}
\hline & Estimate & SE & $C R$ & $p$ \\
\hline \multicolumn{5}{|l|}{ Measurement coefficients } \\
\hline Q1<<Feedback & 1.000 & & & \\
\hline Q2<<Feedback & 0.945 & 0.038 & 24.758 & $* * *$ \\
\hline Q3<<Feedback & 0.995 & 0.045 & 22.265 & $* * *$ \\
\hline Q4<<Knowledge & 0.648 & 0.051 & 12.669 & $* * *$ \\
\hline Q5<<Knowledge & 1.000 & & & \\
\hline Q6<<Knowledge & 0.636 & 0.049 & 13.043 & $* * *$ \\
\hline Q7<<Tech Support T1 & 0.963 & 0.051 & 18.883 & $* * *$ \\
\hline Q8<<Tech Support T1 & 1.000 & & & \\
\hline Q9<<Tech Support T1 & 0.963 & 0.043 & 15.738 & $* * *$ \\
\hline Q7<<Tech Support T2 & 0.903 & 0.050 & 17.911 & $* * *$ \\
\hline Q8<< Tech Support T2 & 1.000 & & & \\
\hline Q9<<Tech Support T2 & 0.624 & 0.039 & 15.982 & $* * *$ \\
\hline Q10<<Engagement & 0.911 & 0.037 & 24.910 & $* * *$ \\
\hline Q11<<Engagement & 0.996 & 0.028 & 35.660 & $* * *$ \\
\hline Q12<<Engagement & 1.000 & & & \\
\hline \multicolumn{5}{|l|}{ Path coefficients } \\
\hline H1: Feedback > Knowledge & 0.116 & 0.057 & 2.045 & * \\
\hline H2: Tech Support T1 > Knowledge & 0.465 & 0.054 & 8.691 & $* * *$ \\
\hline H3: Tech Support T1 > Supervisor E-Com & 0.189 & 0.054 & 3.498 & $* * *$ \\
\hline H4: Tech Support T2 > Alternative Workplace & -0.004 & 0.033 & -0.115 & 0.908 \\
\hline H5: Knowledge > Alternative Workplace & 0.083 & 0.037 & 2.228 & * \\
\hline H6: Supervisor E-Com > Alternative Workplace & 0.182 & 0.030 & 6.004 & $* * *$ \\
\hline H7: Feedback > Engagement & 0.183 & 0.062 & 2.978 & $* *$ \\
\hline H8: Knowledge > Engagement & -0.112 & 0.066 & -1.692 & 0.091 \\
\hline H9: Alt Workplace > Engagement & 0.248 & 0.089 & 2.794 & $* *$ \\
\hline Unexpected Path: Tech Support > Engagement & 0.413 & 0.058 & 7.115 & $* * *$ \\
\hline
\end{tabular}


Fit indices for the default model are $\chi^{2}[120, n=367]=333.620, \chi^{2} / d f=2.780$, CFI $=.940$, and RMSEA $=.070$. The estimated model achieved acceptable goodness-of-fit indices compared with conventional standards (noted above). Modification indices suggested one additional path: a direct path from technology support of work to work engagement. Estimating that path resulted in a slight (but significant) improvement in overall fit $\left(\chi^{2}[119, n=367]=286.949, \chi^{2} / d f=2.411\right.$, CFI $=.953$, RMSEA $\left.=.062 ; \Delta \chi^{2} / d f=46.671\right)$. The bottom section of Table 2 shows the estimated structural path coefficients from the modified model. Figure 2 is the hypothesized model expanded over the two time periods with the standardized path coefficients that have CR estimates greater than 1.96 (i.e., statistically significant at or beyond the $p<.05$ confidence level).

All hypothesized path coefficients were significant at or beyond the $p<.05$ confidence level except those for Hypotheses 4 and 8 . Knowledge to work independently was significantly influenced by both feedback from the work (H1) and technology support of work (H2). The direct path from technology support of work to alternative workplace use (H4) was not significant. This finding suggests that the influence of technology support of work on alternative workplace use is mediated through supervisor electronic communication (H3, H6). While work engagement was significantly influenced by feedback from work (H7), the direct path from knowledge to work independently to work engagement $(\mathrm{H} 8)$ was also non-significant, suggesting that the relationship is also mediated, here through use of alternative workplaces (H5, H9). Alternative workplace use also mediated the effect of supervisor electronic communication on work engagement (H6, H9). The unexpected, but significant, direct path from technology support of work to work engagement (dashed line in Fig. 2) indicates that this relationship is only partially mediated through supervisor electronic communication and alternative workplace use.

\section{T2 comparison of Org1 and Org2}

We replicated the expected measurement model for the combined Org1/Org2 sample in T2. The model fit $(\mathrm{CFI}=.98$, RMSEA $=.06)$ was within the normally accepted range

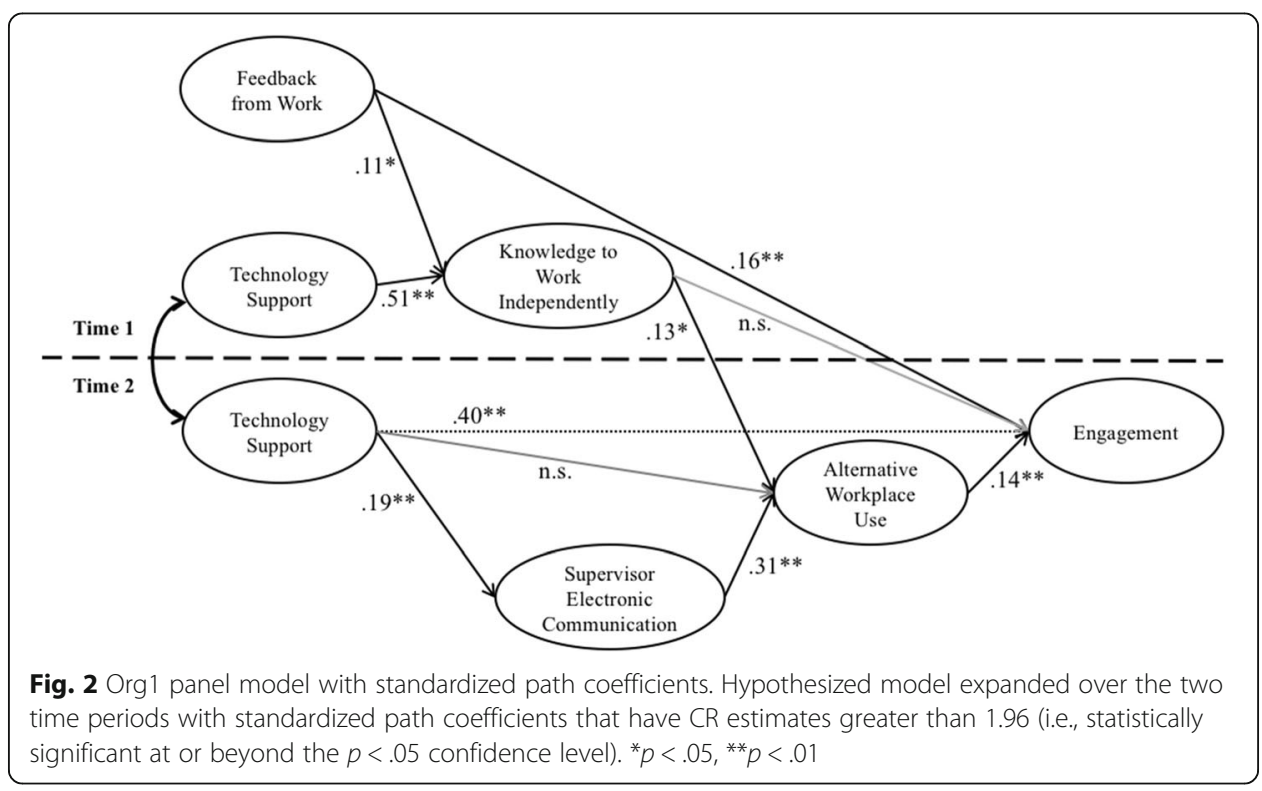


(noted above). The fit indices for the default model (e.g., Fig. 1) estimated on the combined organizations' data are $X^{2}[70, n=1031]=555.93, p<.00$, RMSEA $=.08$, $\mathrm{CFI}=.94, \mathrm{TLI}=.92$. (We test for similarity across the two organizations below.) Again, the estimated model achieved acceptable goodness-of-fit indices (noted above). The modification indices suggested the same additional path as did the panel analysis for Org1: a direct path from technology support of work to work engagement. Figure 3 shows the estimated structural paths (standardized path coefficients) as found in the modified model. Including the estimation of that path resulted in a slight improvement in overall fit $X^{2}[69, n=1031]=494.83, p<.00$, RMSEA $=.08, \mathrm{CFI}=.95, \mathrm{TLI}=.92 ; \Delta \chi^{2} / d f=61.10$. The pattern of path coefficients for the combined sample (Org1 and Org2 at T2) matched those found in the panel analysis.

\section{Test of measurement and structural invariance}

To test for equivalence of the causal structure across the two organizations, we conducted a multi-sample simultaneous structural equation model. First, we used Org1 as the base model because it offered a larger sample size and because it has a long history of flexible work practices. Next, we constrained the parameter estimates for Org2 to mirror Org1 to test for parameter invariance using the automated multiple group analysis in AMOS version 24.0. The procedure constrains successive parameters to be equal across the two organizations, comparing each nested model with the prior less-unconstrained model.

Table 3 provides the item loading estimates for the measurement model, along with the structural path coefficients of the theoretical model estimated for both organization samples without constraint. Table 4 presents the nested model fit comparisons. Chi-square and AIC comparisons show that constraining the structural weights across the two samples does not significantly denigrate the model fit. However, constraining the structural residuals does reduce model fit across the two samples. Structural residuals are the error residual variances associated with the dependent factors in the model. Thus, while the structural model fits the two samples equally, the precision of estimates

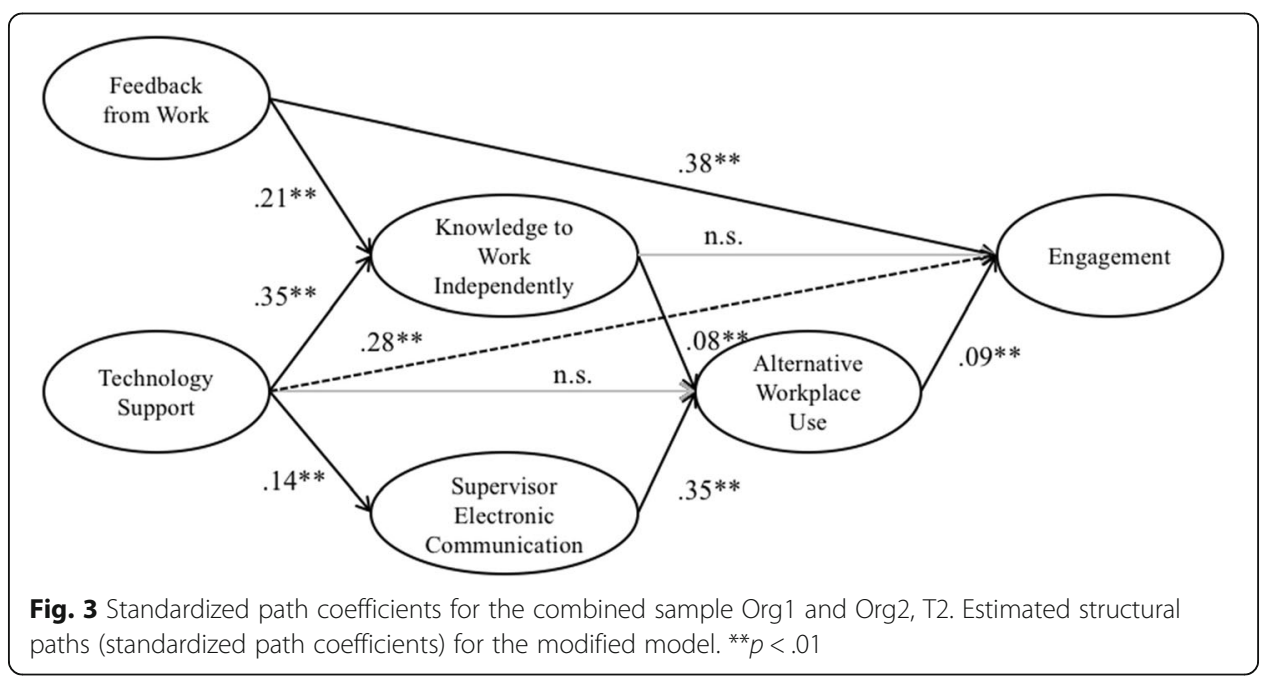


Table 3 Unconstrained model measurement and structural parameter estimates by organization (T2 only)

\begin{tabular}{|c|c|c|c|c|c|c|c|c|}
\hline \multirow[t]{2}{*}{ Measurement and path coefficients } & \multicolumn{4}{|c|}{ Organization 1} & \multicolumn{4}{|c|}{ Organization 2} \\
\hline & Estimate & SE & Std. est & $p$ & Estimate & SE & Std. est & $p$ \\
\hline Q1<<Feedback & 1.00 & & 0.89 & & 1.00 & & 0.89 & \\
\hline Q2<<Feedback & 0.90 & 0.02 & 0.90 & $* *$ & 0.93 & 0.02 & 0.89 & $* *$ \\
\hline Q3<<Feedback & 0.93 & 0.02 & 0.90 & ** & 0.90 & 0.02 & 0.91 & ** \\
\hline Q4<<Knowledge & 0.77 & 0.04 & 0.71 & ** & 0.72 & 0.03 & 0.75 & ** \\
\hline Q5<<knowledge & 1.00 & & 0.83 & & 1.00 & & 0.83 & \\
\hline Q6<<knowledge & 0.74 & 0.04 & 0.79 & $* *$ & 0.80 & 0.03 & 0.79 & $* *$ \\
\hline Q7<<Tech Support & 0.70 & 0.03 & 0.90 & $* *$ & 0.71 & 0.03 & 0.71 & $* *$ \\
\hline Q8<< Tech Support & 1.00 & & 0.71 & & 1.00 & & 0.89 & \\
\hline Q9<<Tech Support & 0.96 & 0.04 & 0.82 & ** & 0.95 & 0.03 & 0.82 & $* *$ \\
\hline Q10<<Engagement & 0.96 & 0.02 & 0.94 & ** & 0.96 & 0.01 & 0.93 & $* *$ \\
\hline Q11<<Engagement & 1.00 & & 0.95 & & 1.00 & & 0.95 & \\
\hline Q12<<Engagement & 0.81 & 0.03 & 0.79 & $* *$ & 0.76 & 0.02 & 0.78 & $* *$ \\
\hline H1: Feedback > Knowledge & 0.18 & 0.03 & 0.21 & $* *$ & 0.18 & 0.03 & 0.21 & $* *$ \\
\hline H2: Tech Support > Knowledge & 0.30 & 0.03 & 0.35 & $* *$ & 0.30 & 0.03 & 0.35 & ** \\
\hline H3: Tech Support > Supervisor E-Com & 0.17 & 0.04 & 0.16 & ** & 0.08 & 0.07 & 0.08 & 0.22 \\
\hline H4: Tech Support > Alternative Workplace & 0.03 & 0.03 & 0.04 & 0.28 & 0.02 & 0.05 & 0.02 & 0.76 \\
\hline H5: Knowledge > Alternative Workplace & 0.02 & 0.03 & 0.01 & 0.55 & 0.15 & 0.06 & 0.16 & $* *$ \\
\hline H6: Supervisor E-Com > Alternative Workplace & 0.22 & 0.02 & 0.35 & ** & 0.27 & 0.04 & 0.36 & ** \\
\hline H7: Feedback > Engagement & 0.49 & 0.03 & 0.38 & $* *$ & 0.40 & 0.03 & 0.39 & $* *$ \\
\hline H8: Knowledge > Engagement & 0.05 & 0.05 & 0.04 & 0.35 & 0.00 & 0.08 & 0.00 & 0.98 \\
\hline H9: Alt Workplace > Engagement & 0.13 & 0.04 & 0.08 & $* *$ & 0.13 & 0.04 & 0.11 & $* *$ \\
\hline Path: Tech Support > Engagement & 0.31 & 0.04 & 0.29 & $* *$ & 0.23 & 0.06 & 0.22 & $* *$ \\
\hline
\end{tabular}

${ }_{* * p}^{*}<.01$

Table 4 Nested model fit comparison

\begin{tabular}{lccccccc}
\hline CMIN & & & & & & & \\
Model & NPAR & CMIN & DF & $p$ & CMIN/DF & $\Delta x^{2}$ & $\Delta d f$ \\
Unconstrained & 58 & 780.16 & 180 & .000 & 4.33 & - & - \\
Structural weights & 52 & 788.70 & 186 & .000 & 4.24 & 8.54 & $6^{\text {n.s. }}$ \\
Structural residuals & 50 & 809.67 & 188 & .000 & 4.31 & 20.97 & $2^{* *}$ \\
Saturated model & 238 & 0.00 & 0 & & & & \\
Independence model & 28 & 8787.20 & 210 & .000 & 41.84 & & \\
Fit indices & Baseline comparisons & & & & \\
Model & NFI & RFI & IFI & TLI & & \\
& Delta1 & rho1 & Delta2 & rho2 & CFI & AIC \\
Unconstrained & 0.911 & 0.896 & 0.930 & 0.918 & 0.930 & 896.16 \\
Structural weights & 0.910 & 0.890 & 0.930 & 0.921 & 0.930 & 892.70 \\
Structural residuals & 0.908 & 0.897 & 0.928 & 0.919 & 0.928 & 909.66 & \\
Saturated model & 1.000 & - & 1.000 & - & 1.000 & 476.00 & \\
Independence model & 0 & 0 & 0 & 0 & 0 & 8843.20 & \\
\hline **p $<.01$ & & & & & &
\end{tabular}

${ }^{* *} p<.01$ 
are not the same across the two models. However, Byrne (2010) points out that constraining structural residuals is an overly stringent criterion and is seldom done when comparing model fit across samples. Byrne and van De Vijver (2010) argue that because the chi-square is an overly sensitive measure of overall fit, as it is affected by the sample size (which here differs considerably between the two organizations) and number of parameters estimated, a more meaningful comparison is the change in CFI. The baseline comparisons in Table 4 show that the constraints of structural weights do not affect the CFI, as it only declines by .002 .

Significant differences in structural parameters left unconstrained, as Table 3 shows, offer an interesting picture of technology support's effect on alternate workplace use. For Org1 in the T2 survey, technology support of work's effect on alternate workplace use is mediated by supervisor electronic communication. For Org2, technology support of work's effect on alternate workplace use is instead mediated by knowledge to work independently. Recalling that alternative workplace use or flexwork is the exception in Org2, it is reasonable to expect that knowledge to work independently would be an enabling factor in one's choice to use alternative workplaces, as Org2 employees would seem less likely to have supervisory involvement in, and organizational support for, their flexible work. This, along with the evidence that the model fits equally well across differing organizational contexts, supports the robustness of the model across differing organizations.

\section{Discussion}

\section{Summary of findings}

Through a panel analysis (T1 and T2) in one organization and a comparison analysis with another organization (at T2), this research addressed a simple model of work design acknowledging how complements to supervisory leadership might influence work engagement (and, thus potentially, performance) in the increasingly frequent environment of flexible work arrangements. Considering characteristics from each of Morgeson and Humphrey's (2008) categories of work design, we found that feedback from work itself, technology support of work, supervisor electronic communication, and use of alternative workplaces all positively influence work engagement, but through different paths, seemingly depending on organizational norms and practices concerning flexible work. When organizational culture and supports for alternative work locations is lacking (Org 2), knowledge to work independently provides the support for alternative workplace use. Knowledge to work independently affected work engagement, via its impact on use of alternative workplaces, for the organization with less background and support for flexible work. In contrast, technological support for supervisor electronic communication provides the support for alternative workplace use in Org 1.

Results show the value of traditional feedback from the work itself, as well as more recent strategies such as technology support of work, in offering opportunities for workers to engage in the performance and process of their work directly. Although not hypothesized, technology support of work directly influenced work engagement in both organizations, as well as being mediated through supervisor use of electronic communication, and knowledge to work independently, depending on the organizational context. 
As expected, feedback from the work itself and technology support of work both were related to knowledge to work independently. However, knowledge to work independently did not directly affect work engagement; rather, it played a mediating role on the influence of use of alternative workplaces. This may be explained by the fact that workers at Org2, with less-supportive flexible work norms and practices, were required to report in to the office for meetings and other collaborative tasks; only workers who could demonstrate a clear motivation for staying home (e.g., to be able to focus on individual knowledge work) would be granted permission to do so. In Org1, with greater experience with and support for flexible work, on the other hand, knowledge to work independently was not a prerequisite for alternative workplace use, and hence did not play a role in people's decisions to work away from the office. That is, alternative work arrangements were perhaps part of an overall more supportive environment rather than an isolated, individual behavior, enabling interdependence among workers across time and distance.

While there is strong evidence for work design focused on complements to supervisory leadership, such as work feedback and technology support of work, these do not completely replace (that is, substitute for) interpersonal interaction with one's supervisor (Men 2014), though the role and modes of leadership may have changed. In Org1, as expected, supervisor electronic communication mediated the relationship between technology support of work and alternative workplace use. In Org2, with less support for and experience with flexible work, technology support of work was unrelated to the level of supervisor electronic communication, though level of electronic communication with the supervisor positively influenced alternative workplace use. This may suggest that, while supervisor electronic communication is important for all alternative workplace use, in organizations experienced with flexible work, other technology work systems may obviate or complement the use of, or need for, this form of communication.

\section{Theoretical and managerial contributions \\ Theoretical implications}

Technology to support work, mediated modes of communicating with supervisors, and alternative workplace use are all growing aspects of work design. While research has provided mixed support for the substitutes for leadership research (see Dionne et al. 2005), the present results affirm that there is value in a complements to supervisory leadership approach given greater integration of technology into work and greater distribution of work across time, locations, and people. Digital work contexts may offer less, though still some, opportunity for the application of traditional supervisory leadership (Avolio et al. 2014; Hoch and Kozlowski 2014) - thus the importance of our focus on complements to supervisory leadership where there is a presumption that supervisory leadership is also part of the individual work context. Previous research examined the value of shared leadership (D'Innocenzo et al. 2016; Hoch and Kozlowski 2014) and structural supports (Hoch and Kozlowski 2014) in team contexts, as well as self-leadership in individual and team contexts (Breevaart et al. 2016; Millikin et al. 2010). However, this is the first study to address the value of complements to supervisory leadership in individual contexts with digital work arrangements. Our model and the results propose 
complements such as feedback from the task itself and technology support of work as important predictors of work engagement.

This also appears to be a step forward given the emergence of a landscape of leadership in environments with more diffuse organizational boundaries, technology support, and greater flexibility. The autonomy and flexibility afforded by alternative workplaces and work structures supported by technology, supervisor electronic communications, and knowledge to work independently strengthens work engagement. Consistent with Pierce et al. (2009), we suggest an expansion and elaboration of the job characteristics model (Hackman and Oldham 1975; Humphrey et al. 2007). We agree with the more individual differences approach Pierce et al. suggest and add that the model needs to identify how technological supports, alternative work contexts, and alternative organizational forms affect work engagement (paralleling their focus on psychological ownership). While our data are focused on just one section of this landscape, complements to supervisory leadership in an individual work context as opposed to teams or projects, for example, we believe there is a theoretical contribution in highlighting the broader spectrum of possible effects. Complements to supervisory leadership are aligned with work design approaches that focus on non-hierarchical approaches to support control and coordination of work (e.g., Cleveland 1985; Ebert and Freibichler 2017; Fjeldstad et al. 2012; Huber 1990; Lawler 1988; Taylor and Van Every 1993). We see the complements approach as a contribution to this stream of research as it may serve as a conceptual bridge from the role of traditional supervisory leadership to full substitutes emerging from technological enhancements to work.

We find some organizational differences regarding how leadership complements affect work engagement. Technology support of work and knowledge to work independently had different roles in influencing engagement in organizations with more and less support for flexible work. The effects played out here in the context of flexible work and using communication technologies, but may be interesting contributions as we consider relationships with even more diffuse connections to supervisory leadership, such as freelancing or crowdsourcing (settings falling into the category of non-standard employment, c.f., Ashford et al. 2007; Petriglieri et al. 2018).

\section{Managerial implications}

We began this research with an appreciation for the opportunities and challenges provided by shifts to more fluid forms of organizing (e.g., employees working away from the office and increased use of freelancers) and digital technologies. The results suggest several practical implications for managers and organizational designers.

Feedback from the work itself, foundational to early work on human factors and job enrichment, remains a powerful benefit for work engagement. It is important to note that our results follow from standard practice in the two organizations rather than from any program intentionally designed to leverage feedback. In settings where tools and training are designed to improve feedback, especially feedback focused on building greater knowledge to work independently of supervision, we may see even stronger engagement effects.

Practices, such as operational transparency (Buell et al. 2016) that increase visibility into the cause and effect of work outcomes, stand to increase knowledge, engagement 
and performance (for an interesting example in the context of Major League Baseball umpires, see Mills 2017). In more digital organizations, we expect such transparency becomes easier to offer as measurement of work is more widespread, and more work is conducted through information and communication systems that record activities and transactions. Care in implementation is suggested, however; monitoring data available to the individual or team can result in different outcomes if that data is also available to management (Bernstein 2012; Bernstein 2017). Individual or team privacy may be needed for transparency to not have unintended negative consequences.

There are similar complexities when working with technology support. We believe the most powerful tools will specifically offer opportunities to learn how to work independently of supervision, but also suggest or trigger communication with supervisors. Machine learning techniques may offer new strategies for work (Brynjolfsson and Mitchell 2017). As we look to the opportunities offered by machine learning (Faraj et al. 2018), this research suggests value in approaches that bring individuals deep insights from their work and where that work fits in the flow of the organization.

Finally, managers should note the positive effect on work engagement of alternative workplace use, supported by appropriate knowledge and electronic communication with supervisors. The US Bureau of Labor Statistics reports that the proportion of workers doing "some or all of their work at home grew from 19 percent in 2003 to 24 percent in 2015" (Bureau of Labor Statistics 2016). Construction and use of coworking spaces, typically urban hubs where employees and/or freelancers share a workspace offered by a third-party provider, are on the rise (Johns and Gratton 2013). While it may be counter-intuitive that working away from the office would increase engagement with one's work, we believe the key is in recognizing that this finding is more likely in conjunction with thoughtful levels of support.

\section{Limitations and future research}

The field research nature of this work limited some aspects of the study design. While the analyses include both panel and cross-sectional comparisons, we were not able to obtain panel data for the second organization. The individual-worker focus meant we could not control or test for team/group differences.

Both the results and the limitations of this work suggest opportunities for future research. Work practices evolve. Future research that tracks this evolution, as well as refines the model with greater detail around specific forms of feedback and technology support of work, will be valuable. While this sample consisted of fairly traditional full-time employees, there is opportunity to validate the model with a broader population (e.g., including both traditional and crowd-sourced freelancers).

Future research should extend the model and its assessment to include objective work task feedback and performance measures via supporting technologies or performance measures provided by a supervisor or independent party. Prior research suggests that increased work engagement results in better performance (e.g., Bakker et al. 2012; Rich et al. 2010; Salanova et al. 2005; Zhong et al. 2016). With the increasing digitalization of work, access to more refined information around work process and outcomes provide unique opportunities for more nuanced examinations. 
The results showed a significant relationship between technology support of work and knowledge to work independently. A better understanding of the forms that such technology support takes would help elucidate this link. Our measure of technology support of work focused on technology that supported knowing what needed to be done, motivation to do the work well, and work process. It may be valuable to provide more fine-grained assessments around technologies, such as artificial intelligence, that support by replacing (substituting) human work versus leveraging (complementing) human work (e.g., Brynjolfsson and McAfee 2014; Brynjolfsson and Mitchell 2017). Also, the specific items in the technology support of work scale did not specifically exclude technology-enabled communication with the supervisor. Thus, the technology support of work scale should be adapted to avoid any possible confounding of the technology and communication effect (Bloom et al. 2014) and to emphasize technology support related to the work itself. In addition, future research could include likely antecedents to knowledge to work independently, such as education, organizational assimilation, organizational level, and domain expertise.

As noted above, there are clear opportunities to extend the model both as it relates to job characteristics (e.g., Pierce et al. 2009) and the increasingly digital context of work. As more organizational work involves information and communication technologies (Rice and Leonardi 2013), we may be able to design research that does a better job of parsing leadership, self-leadership, motivation, and supervision supported by technology. Research on the efficacy of substitutes/complements for leadership has provided mixed results (Podsakoff et al. 1993), but with more work and work processes becoming visible through technology mediation, we gain more precise metrics and insights through performance dashboards or other tools.

Here we used fairly traditional considerations of work design to push our understanding of complements to supervisory leadership. This is a strength of the work as it provides a tight tie to well-understood practice. However, technology innovations, including technology taking on a more performative role, open avenues for more extreme theorizing. Jordon (2017), for example, asked, "what happens to chains of command, risk mitigation, and consensus decisions as algorithms drive more and more operational, and soon strategic, processes?” (p. 8). Additionally, blockchain capabilities, where an electronic distributed ledger provides a permanent, verifiable, record of transactions (not just cryptocurrencies, Iansiti and Lakhani 2017) between parties, offer opportunities for new theories of organization (Makadok et al. 2018).

Our foundational use of Morgeson and Humphrey's (2008) task, social, and contextual categories of work design, divided across characteristics of the work or the worker, could be reconsidered in a world where agency can also be taken on by technologies that may function as black boxes in terms of decision making (Voosen 2017)-either because they are not built to offer transparency into the machinations or because the process is too complex for humans to understand. That is, some or many characteristics of our decisions about tasks may be embedded within the technology, and not experienced by the worker.

We speculate that the locus and form of leadership activity will become less important in more digital organizations. Kerr and Jermier (1978), Lawler (1988), and others noted above, outlined the possibilities of substitutes for leadership. We have focused on the opportunities for complements to supervisory leadership. The next step may be to test 
whether the source (e.g., one's supervisor or a knowledge network) is less important than the action (e.g., knowledge support). Taking this a step further, greater precision around leadership effects and personal needs (e.g., Breevaart et al. 2016) might stimulate a personalized theory of leadership similar to efforts in personalized medicine (Schork 2015).

\section{Conclusions}

Tyre and Orlikowski (1994), and more recently Sun (2012), found that novel situations and/or situations where the outcomes did not match expectations could trigger a round of (or foster a window of opportunity for) adjustment in how work is done. Ongoing shifts in technology and expectations around work are likely to provide ample impetus for adjustments to work design. Our results offer a framework to leverage self-leadership, and other complements to supervisory leadership, in more and less virtual, flexible, distributed, and cross-organizational settings.

\section{Endnote}

${ }^{1}$ While we do not think it is likely in the current context of our research, we do acknowledge the possibility of technology support of work reducing knowledge to work independently (deskilling) if the technology takes over the work rather than serving in a supporting role.

\section{Appendix}

\section{Measures used in this study}

Response choices for Feedback from Work Itself, Knowledge to Work Independently, Technology Support of Work and Work Engagement: from 1 (strongly disagree) to 7 (strongly agree). Supervisor Electronic-Communication and Alternative Workplace Use response choices: from 1 (never) to 7 (every day).

Feedback from work itself: My work provides me with feedback on how well I am doing; My work provides me with the feeling that I know whether I am performing well or poorly; My work provides me with the opportunity to find out how well I am performing.

Knowledge to work independently: I have the job knowledge to act independently of my immediate supervisor in performing my work; I have all the required knowledge to be my own boss in my work; I have enough knowledge to handle most situations that I face in my work.

Technology support of work: I use tools/technologies that support me in knowing what needs to be done; I use tools/technologies that support my motivation to do the work well; I use tools/technologies that are helpful when I am uncertain about the best way to do the work.

Work engagement: I am enthusiastic about my job; My job inspires me; I am proud of the work that I do.

Supervisor electronic communication: Communicate via text messages with your supervisor; Talk with your supervisor on the phone; Communicate with your supervisor via email.

Alternative workplace use: Work at home; Work at other company's location; Work in a hotel; Work at a library. 


\section{Acknowledgements}

We would like to acknowledge the support of Prof. Anu Sivunen, Prof. Satu Koivisto, and Prof. Karen K. Myers, for their work on the broader CityWorkLife project. We appreciate Prof. Cristina Gibson's comments on an earlier draft. Additionally, we thank the two Finnish organizations who provided access for the field data. Without their support, this research could not have happened.

Funding

TEKES (now Business Finland, https://www.businessfinland.fi) provided funding by a grant to the CityWorkLife project of Aalto University.

\section{Availability of data and materials}

Additional background is available by communication with the corresponding author. Raw data is not available given the confidentiality agreements made with the source organizations.

\section{Authors' contributions}

All four authors work in the area of management and the future of work and contributed to the design of the survey and study, as well as writing and revising the manuscript. Additionally, EM served as the research site leader, RER provided extensive data management, and JES provided advanced structural model analytics. The order of authorship is an indication of tenure on the manuscript rather than intellectual contribution. All authors read and approved the final manuscript.

\section{Competing interests}

The authors declare that they have no competing interests.

\section{Publisher's Note}

Springer Nature remains neutral with regard to jurisdictional claims in published maps and institutional affiliations.

\section{Author details}

'Leavey School of Business, Santa Clara University, 500 El Camino Real, Santa Clara, CA 95053, USA. ${ }^{2}$ Department of Industrial Engineering and Management, Aalto University School of Science, Maarintie 8, 02150 Espoo, Finland. ${ }^{3}$ Lerner College of Business \& Economics, University of Delaware, Newark, DE 19716, USA. ${ }^{4}$ Department of Communication, University of California, Santa Barbara, CA 93106-4020, USA.

\section{Received: 4 December 2017 Accepted: 22 August 2018}

Published online: 26 September 2018

\section{References}

Annett J (1969) Feedback and human behavior. Penguin Books, Baltimore

Ashford SJ, George E, Blatt R (2007) 2 old assumptions, new work: the opportunities and challenges of research on nonstandard employment. Acad Manag Ann 1:65-117

Avolio BJ, Sosik JJ, Kahai SS, Baker B (2014) E-leadership: re-examining transformations in leadership source and transmission. Leadersh Q 25:105-131. https://doi.org/10.1016/j.leaqua.2013.11.003

Bakker AB, Demerouti E, ten Brummelhuis LL (2012) Work engagement, performance, and active learning: the role of conscientiousness. J Vocat Behav 80:555-564

Bakker AB, Schaufeli WB, Leiter MP (2008) Work engagement: an emerging concept in occupational health psychology. Work Stress 22:187-200

Barley S, Bechky B, Milliken F (2017) The changing nature of work: careers, identities, and work lives in the 21st century. Acad Manag Discov 3:111-115. https://doi.org/10.5465/amd.2017.0034

Bélanger F, Allport CD (2008) Collaborative technologies in knowledge telework: an exploratory study. Inform Syst J 18:101-121

Bernstein ES (2012) The transparency paradox: a role for privacy in organizational learning and operational control. Admin Sci Q 57:181-216

Bernstein ES (2017) Making transparency transparent: the evolution of observation in management theory. Acad Manag Ann $11: 217-266$

Bilodeau IM (1966) Acquisition of skill. Academic Press, New York

Bloom N, Garicano L, Sadun R, Van Reenen J (2014) The distinct effects of information technology and communication technology on firm organization. Manag Sci 60:2859-2885

Bonet R, Salvador R (2017) When the boss is away: manager-worker separation and worker performance in a multisite software maintenance organization. Organ Sci 28:244-261. https://doi.org/10.1287/orsc.2016.1107

Breevaart K, Bakker AB, Demerouti E, Derks D (2016) Who takes the lead? A multi-source diary study on leadership, work engagement, and job performance. J Organ Behav 37:309-325. https://doi.org/10.1002/job.2041

Brynjolfsson E, McAfee A (2014) The second machine age: work, progress, and prosperity in a time of brilliant technologies. WW Norton \& Company, New York

Brynjolfsson E, Mitchell T (2017) What can machine learning do? Workforce implications. Science 358:1530-1534

Buell RW, Kim T, Tsay C-J (2016) Creating reciprocal value through operational transparency. Manag Sci 63:1673-1695

Bureau of Labor Statistics (2016) 24 percent of employed people did some or all of their work at home in 2015. The Economics Daily

Byrne BM (2010) Structural equation modeling with AMOS: basic concepts, applications, and programming, 2nd edn. Routledge, New York

Byrne BM, van de Vijver FJR (2010) Testing for measurement and structural equivalence in large-scale cross-cultural studies: addressing the issue of nonequivalence. Int J Test 10:107-132 
Campbell JP, Dunnette E, Lawler E, Weick KE (1970) Managerial behavior, performance and effectiveness. McGraw-Hill, New York

Cleveland H (1985) The twilight of hierarchy: speculations on the global information society. Publ Admin Rev 45:185-195

D'Innocenzo L, Mathieu JE, Kukenberger MR (2016) A meta-analysis of different forms of shared leadership-team performance relations. J Manag 42:1964-1991

D'Souza GC, Colarelli SM (2010) Team member selection decisions for virtual versus face-to-face teams. Comput Human Behav 26:630-635. https://doi.org/10.1016/j.chb.2009.12.016

Dascal M, Dror IE (2005) The impact of cognitive technologies. Pragmat Cogn 13:451-457

Davenport TH (2005) Thinking for a living: how to get better performance and results from knowledge workers. Harvard Business Press, Boston

Dionne SD, Yammarino FJ, Atwater LE, James LR (2002) Neutralizing substitutes for leadership theory: leadership effects and common-source bias. J Appl Psychol 87:454-464

Dionne SD, Yammarino FJ, Howell JP, Villa J (2005) Substitutes for leadership, or not. Leadersh Q 16:169-193

Ebert P, Freibichler W (2017) Nudge management: applying behavioural science to increase knowledge worker productivity. J Organ Des 6:1-6

Faraj S, Pachidi S, Sayegh K (2018) Working and organizing in the age of the learning algorithm. Inform Organ 28:62-70

Fjeldstad ØD, Snow CC, Miles RE, Lettl C (2012) The architecture of collaboration. Strat Manag J 33:734-750

Forman C, King JL, Lyytinen K (2014) Special section introduction—information, technology, and the changing nature of work. Inform Syst Res 25:789-795

Gajendran RS, Harrison DA (2007) The good, the bad, and the unknown about telecommuting: meta-analysis of psychological mediators and individual consequences. J Appl Psychol 92:1524-1541

Galbraith JR (2012) The future of organization design. J Organ Des 1:3-6. https://doi.org/10.7146/jod.6332

Gallup, Inc. (2017) State of the global workplace - executive summary [Online] Available at http://news.gallup.com/reports/ 220313/state-global-workplace-2017.aspx. Accessed 2 Jan 2018

Gerards R, de Grip A, Baudewijns C (2018) Do new ways of working increase work engagement? Pers Rev 47:517-534

Gibson CB, Gibbs JL, Stanko TL, Tesluk P, Cohen SG (2011) Including the "I" in virtuality and modern job design: extending the job characteristics model to include the moderating effect of individual experiences of electronic dependence and copresence. Organ Sci 22:1481-1499

Gilson LL, Maynard MT, Jones Young NC, Vartiainen M, Hakonen M (2015) Virtual teams research: 10 years, 10 themes, and 10 opportunities. J Manag 41:1313-1337

Goodman JS (1998) The interactive effects of task and external feedback on practice performance and learning. Organ Behav Hum Decis Process 76:223-252

Greller MM, Herold DM (1975) Sources of feedback: a preliminary investigation. Organ Behav Hum Perform 13:244-256

Hackman JR, Oldham GR (1975) Development of the job diagnostic survey. J Appl Psychol 60:159-170

Haddon L, Brynin M (2005) The character of telework and the characteristics of teleworkers. New Tech Work Employ 20:34-46

Hall DT, Lawler EE (1968) Unused potential in research and development organizations. R Manag 12:339-354

Hoch JE, Kozlowski SWJ (2014) Leading virtual teams: hierarchical leadership, structural supports, and shared team leadership. J Appl Psychol 99:390

Hu L, Bentler PM (1999) Cutoff criteria for fit indexes in covariance structure analysis: conventional criteria versus new alternatives. Struct Equ Modeling 6:1-55

Huber GP (1990) A theory of the effect of advanced information technologies on organizational design, intelligence, and decision making. Acad Manag Rev 15:47-71

Humphrey SE, Nahrgang JD, Morgeson FP (2007) Integrating motivational, social, and contextual work design features: a meta-analytic summary and theoretical extension of the work design literature. J Appl Psychol 92:1332-1356

lansiti M, Lakhani KR (2017) The truth about blockchain. Har Bus Rev 95:118-127

Ilgen DR, Fisher CD, Taylor MS (1979) Consequences of individual feedback on behavior in organizations. J Appl Psychol 64: 349-371

Jermier JM, Kerr S (1997) Substitutes for leadership: their meaning and measurement—contextual recollections and current observations. Leadersh Q 8:95-101

Johns T, Gratton L (2013) The third wave of virtual work. Har Bus Rev 91:66-73

Jordan JM (2017) Challenges to large-scale digital organization: the case of Uber. J Organ Des 6:11

Keller RT (2006) Transformational leadership, initiating structure, and substitutes for leadership: a longitudinal study of research and development project team performance. J Appl Psychol 91:202

Kerr S, Jermier JM (1978) Substitutes for leadership: their meaning and measurement. Organ Behav Hum Perform 22: 375-403

Knight C, Patterson M, Dawson J (2017) Building work engagement: a systematic review and meta-analysis investigating the effectiveness of work engagement interventions. J Organ Behav 38:792-812

Kossek E, Michel J (2011) Flexible work scheduling. In: Zedeck S (ed) APA handbook of industrial-organizational psychology, vol 1. American Psychological Association, Washington, D.C., pp 535-572

Kubicek B, Korunka C, Paškvan M, Prem R, Gerdenitsch C (2014) Changing working conditions at the onset of the twenty-first century: facts from international datasets. In: The impact of ICT on quality of working life. Springer, Dordrecht, pp 25-42

Lawler EE III (1988) Substitutes for hierarchy. Organ Dynam 17:5-16

Leiter MP, Bakker AB (2010) Work engagement: introduction, Work engagement: A handbook of essential theory and research, pp 1-9

Leonardi PM (2014) Social media, knowledge sharing, and innovation: toward a theory of communication visibility. Inform Syst R 25:796-816

Leslie L, Manchester C, Park T-Y, Mehng SA (2012) Flexible work practices: a source of career premiums or penalties? Acad Manage J 2010.0651

Lovelace KJ, Manz CC, Alves JC (2007) Work stress and leadership development: the role of self-leadership, shared leadership, physical fitness and flow in managing demands and increasing job control. Hum Resource Manag Rev 17:374-387 
Makadok R, Burton R, Barney J (2018) A practical guide for making theory contributions in strategic management. Strat Manag J 39:1530-1545

Mark G (2002) Extreme collaboration. Commun ACM 45:89-93

McCormick EJ (1970) Human factors engineering. McGraw-Hill, New York

Men LR (2014) Strategic internal communication: transformational leadership, communication channels, and employee satisfaction. Manage Commun Q 28:264-284

Millikin JP, Hom PW, Manz CC (2010) Self-management competencies in self-managing teams: their impact on multi-team system productivity. Leadersh Q 21:687-702. https://doi.org/10.1016/j.leaqua.2010.07.001

Mills BM (2017) Technological innovations in monitoring and evaluation: evidence of performance impacts among major league baseball umpires. Lab Econ 46:189-199

Morgeson FP, Humphrey JP (2008) Job and team design: toward a more integrative conceptualization of work design. In: Martocchio JJ (ed) Research in personnel and human resources management, vol 27. Emerald Group Publishing Limited, Bradford, pp 39-91

Nelson RR, Winter SG (1982) An evolutionary theory of economic change. Harvard University Press, Cambridge

Nilles JM (1982) Telecommuting: the wired worker. VocEd 57:47-49

Nonaka I (1994) A dynamic theory of organizational knowledge creation. Organ Sci 5:14-37

Nye CD, Drasgow F (2011) Assessing goodness of fit: simple rules of thumb simply do not work. Organ Res Meth 14:548-570

Oldham GR, Fried Y (2016) Job design research and theory: past, present and future. Organ Behav Hum Decis Process 136: 20-35. https://doi.org/10.1016/j.obhdp.2016.05.002

Olson MH (1983) Remote office work: changing work patterns in space and time. Comm ACM 26:182-187

Parker SK, Morgeson FP, Johns G (2017) One hundred years of work design research: looking back and looking forward. J Appl Psychol 102:403

Petriglieri G, Ashford SJ, Wrzesniewski A (2018) Agony and ecstasy in the gig economy: cultivating holding environments for precarious and personalized work identities. Admin Sci Q https://doi.org/10.1177/0001839218759646

Petrou P, Demerouti E, Peeters MCW, Schaufeli WB, Hetland I (2012) Crafting a job on a daily basis: contextual correlates and the link to work engagement. J Organ Behav 33:1120-1141

Pierce JL, Jussila I, Cummings A (2009) Psychological ownership within the job design context: revision of the job characteristics model. J Organ Behav 30:477-496

Pitt-Catsouphes M, Matz-Costa C (2008) The multi-generational workforce: workplace flexibility and engagement. Community Work Fam 11:215-229

Podsakoff NP, MacKenzie SB (1994) An examination of the psychometric properties and nomological validity of some revised and reduced substitutes for leadership scales. J Appl Psychol 79:702-713

Podsakoff PM, MacKenzie SB, Bommer WH (1993) Meta-analysis of the relationships between Kerr and Jermier's substitutes for leadership and employee job attitudes, role perceptions, and performance. J Appl Psychol 81:380-399

Raghuram S, Garud R, Wiesenfeld B, Gupta V (2001) Factors contributing to virtual work adjustment. J Manage 27:383-405

Rice RE (1980) The impacts of computer-mediated organizational and interpersonal communication. In: Williams M (ed) Annual review of information science and technology, vol 15. Knowledge Industry Publications, White Plains, pp 221-249

Rice RE (2017) Flexwork, boundaries, and work-family conflicts: how ICTs and work engagement influence their relationship. In: Hertel G, Stone D, Johnson RD, Passmore J (eds) Handbook of the psychology of the internet at work, Industrial \& organizational psychology series. Wiley Blackwell, London, pp 175-193

Rice RE, Bair J (1984) New organizational media and productivity. In: Rice RE (ed) The new media: communication, research and technology. Sage, Beverly Hills, pp 185-215

Rice RE, Cooper SD (2010) Organizations and unusual routines: a systems analysis of dysfunctional feedback processes. Cambridge University Press, New York

Rice RE, Leonardi PM (2013) Information and communication technology in organizations, 2000-2011. In: Putnam L, Mumby DK (eds) Sage handbook of organizational communication, 3rd edn. Sage, Thousand Oaks, pp 425-448

Rich BL, Lepine JA, Crawford ER (2010) Job engagement: antecedents and effects on job performance. Acad Manag J 53:617-635

Richman AL, Civian JT, Shannon LL, Jeffrey Hill E, Brennan RT (2008) The relationship of perceived flexibility, supportive worklife policies, and use of formal flexible arrangements and occasional flexibility to employee engagement and expected retention. Community Work Fam 11:183-197

Ruth S (2011) The dark side of telecommuting-is a tipping point approaching? GMU School of Public Policy Research Paper doi:https://doi.org/10.2139/ssrn.1880895

Saks AM (2006) Antecedents and consequences of employee engagement. J Manag Psychol 21:600-619

Salanova M, Agut S, Peiro JM (2005) Linking organizational resources and work engagement to employee performance and customer loyalty: the mediation of service climate. J Appl Psychol 90:1217

Santos CM, Passos AM, Uitdewilligen S, Nübold A (2016) Shared temporal cognitions as substitute for temporal leadership: an analysis of their effects on temporal conflict and team performance. Leader Q 27:574-587

Schaufeli WB, Bakker AB (2004) Job demands, job resources and their relationship with burnout and engagement: a multisample study. J Organ Behav 25:293-315

Schaufeli WB, Bakker AB, Salanova M (2006) The measurement of work engagement with a short questionnaire a crossnational study. Educ Psychol Meas 66:701-716

Schork NJ (2015) Personalized medicine: time for one-person trials. Nature 520:609-611

Snow CC, Fjeldstad ØD, Langer AM (2017) Designing the digital organization. J Organ Des 6:7

Stanford J (2017) The resurgence of gig work: historical and theoretical perspectives. Econ Lab Relat Rev 28:382-401 https://doi.org/10.1177/1035304617724303

Stewart GL, Courtright SH, Manz CC (2011) Self-leadership: a multilevel review. J Manage 37:185-222

Sun H (2012) Understanding user revisions when using information system features: adaptive system use and triggers. MIS Q 36:453-478

Tapscott D, Ticoll D (2003) The naked corporation: how the age of transparency will revolutionize business. Free Press, New York

Taylor JR, van Every EJ (1993) The vulnerable fortress: bureaucratic organization and management in the information age. University of Toronto Press, Toronto 
Tyre MJ, Orlikowski WJ (1994) Windows of opportunity: temporal patterns of technological adaptation in organizations. Organ Sci 5:98-118

Vanderfeesten I, Reijers HA (2006) How to increase work autonomy in workflow management systems? Manag Res News 29: 652-665

Voosen P (2017) How Al detectives are cracking open the black box of deep learning. Sci Magazine doi: https://doi.org/10. 1126/science.aan7059

Wiesenfeld BM, Raghuram S, Garud R (1999) Managers in a virtual context: the experience of self-threat and its effects on virtual work organizations. J Organ Behav 6:31-44

Willis Towers Watson (2017) Employee engagement insights and trends review. https:/www.towerswatson.com/en/Insights/ IC-Types/Ad-hoc-Point-of-View/2016/05/Employee-surveys-views-and-insights. Accessed 15 June 2017

Xanthopoulou D, Bakker AB, Demerouti E, Schaufeli WB (2009) Reciprocal relationships between job resources, personal resources, and work engagement. J Vocat Behav 74:235-244

Zhong L, Wayne SJ, Liden RC (2016) Job engagement, perceived organizational support, high-performance human resource practices, and cultural value orientations: a cross-level investigation. J Organ Behav 37:823-844

Submit your manuscript to a SpringerOpen ${ }^{\circ}$ journal and benefit from:

- Convenient online submission

- Rigorous peer review

- Open access: articles freely available online

High visibility within the field

- Retaining the copyright to your article

Submit your next manuscript at $\boldsymbol{\nabla}$ springeropen.com 